Sneath, P. H. A. (1956). J. gen. Microbiol. 15, 99-105

\title{
The Change from Polar to Peritrichous Flagellation in Chromobacterium spp.
}

\author{
By P. H. A. SNEATH \\ National Institute for Medical Research, Mill Hill, London, N.W. 7
}

SUMMARY: Some strains of Chromobacterium exhibit either polar or mixed polar and peritrichous flagellation according to the conditions of culture. Polar and lateral flagella differ in the site of insertion, the wavelength, ease of staining, and in antigenic composition. Peritrichous flagellation is greatest in young cultures on solid media and is least in liquid media. The peritrichate flagella disappear in old agar plate cultures, leaving polar flagellated organisms.

The arrangement of flagella has an important place in modern systems of bacterial classification. A species is usually considered to have either polar or peritrichate flagella but not both, and this feature is one of the main distinctions between, for instance, the pseudomonads and the enterobacteria. It was noticed that one strain of Chromobacterium appeared to possess two types of flagellum-a polar flagellum and a lateral flagellum of shorter wavelength. This was misinterpreted (Sneath, Whelan, Singh \& Edwards, 1953) until the same appearance was found in the majority of strains of Chromobacterium (sensu stricto-i.e. the 'Bacterium violaceum' group). Published descriptions of flagellation in the genus vary considerably, and it is clear that this appearance has been observed before, but without attracting comment. Thus CruessCallaghan \& Gorman (1933) published photographs similar to Pl. 1, fig. 2, but attributed the variation to species differences; this has not been confirmed (Sneath, 1956). Lehmann \& Neumann (1899, 1, Pl. 23, figs. XI, XII; 2, p.180) showed drawings of predominantly peritrichate and predominantly polar strains, and commented that some strains showed both forms. Bampton (1913) somewhat ambiguously reported 'Geisseln 3-4 peritrich, 1-2 polar'. Most other authors report a single polar flagellum. Leifson \& Hugh (1953) described certain strains of Aeromonas and Vibrio spp. which may show either peritrichate or polar flagella. In Aeromonas sp. the organisms in early phases of growth showed peritrichate flagella, and in old cultures only polar flagella.

\section{METHODS}

Strains. The strains are those described previously (Sneath, 1956), all belonging to the 'Bacterium violaceum' group.

Flagella staining. The organisms were stained by the method of Leifson (1951). Cultures on solid media were suspended in distilled water, care being taken to avoid the picking up of fragments of medium. Liquid cultures were washed three times by centrifugation with distilled water before staining.

Media. Nutrient broth was that of Hartley (1922), and nutrient agar was made by adding to it $1.5 \%(\mathrm{w} / \mathrm{v})$ Japanese agar. Blood agar was nutrient 
agar containing $5 \%(v / v)$ sterile defibrinated horse blood. The glucose ammonia medium was that of Mandelstam (1954) with omission of sodium lactate.

Incubation. For mesophilic strains the incubation temperature used routinely was $30^{\circ}$, and for psychrophilic strains $25^{\circ}$.

Antisera and agglutination tests. Antisera were prepared by injecting washed organisms (suspended in $\mathbf{0 . 0 4} \%$ formaldehyde in physiological saline) into rabbits intravenously three times a week, increasing the dose gradually from about $10^{8}$ to $10^{9}$ organisms. Seven injections were given. The suspension of strain DK with only polar flagella (referred to subsequently as polar suspension) was a nutrient broth culture grown for $24 \mathrm{hr}$. at $35^{\circ}$. The suspension of the same strain with both polar and lateral flagella (peritrichate suspension) was the growth from a blood agar culture of strain DK grown at $30^{\circ}$ for $18 \mathrm{hr}$. Suspensions prepared in the same way, and similarly formalized, were used for absorption and agglutination, and were all stained to confirm that they were in the required phase. Deflagellated organisms were prepared by treating living cultures in a Waring Blendor until there were very few motile organisms, and few flagellated organisms in stained preparations; the time required was usually about $6 \mathrm{~min}$. Agglutination tests were performed in $\mathbf{0} \cdot 17 \%$ sodium chloride: $0.25 \mathrm{ml}$. amounts of diluted antiserum and of suspension (of an opacity of 5.5 International Opacity Units (World Health Organization, 1954)) were mixed in Dreyer's tubes and incubated at $56^{\circ}$. The titre given is the reciprocal of the final dilution of antiserum in the last tube with agglutination just visible to the naked eye.

\section{RESULTS}

Two types of organism were found: those with only a single polar flagellum (Pl. 1, fig. 1), and those with lateral flagella in addition to a single polar flagellum (Pl. 1, fig. 2). For brevity the former are referred to as polar organisms and the latter as peritrichate organisms. It was uncommon to see organisms with lateral flagella which lacked a polar flagellum, or to see organisms with two polar flagella (unless they were dividing, and they were then always at opposite poles).

All strains were examined after $18 \mathrm{hr}$. growth on nutrient agar plates, and thirty out of thirty-eight strains showed both polar and lateral flagella (Sneath, 1956). Some strains were studied extensively, and these can be roughly divided into two groups: (1) those showing only polar flagellation (Pl. 1, fig. 1) under all conditions examined (strains FH, MW, AM and MH), and (2) those showing during early growth on agar many lateral flagella, usually 4-6, of great length and of very short wavelength (Pl. 1, fig. 2), in addition to the polar flagellum (strains LG, LW, BN, BH, RT, DK, SH, NT, $\mathrm{RV}$ and MK). With all these strains the number of lateral flagella decreased as the plate cultures became aged, and usually only polar flagellated organisms were found after 2 days of incubation. The two classes were not sharply defined, and some strains, e.g. BH, appeared intermediate (with only a few lateral flagella). The classes did not appear to be related to other characteristics of the strains, such as pathogenicity or biochemical reactions. All attempts 
to obtain stable variants in one or other phase have proved unsuccessful, but the existence of strains possessing only polar flagella suggests that these may be variants which have lost the ability to produce lateral flagella.

\section{Differences between polar and lateral flagella}

The differences between the two types of flagellum, as seen in stained preparations, is generally quite clear. Although there is some variation from strain to strain, most strains possess a short polar flagellum, 2-4 $\mu$. long, with a wavelength $c .2 \mu$. and amplitude $c .0 \cdot 35 \mu$. and lateral flagella 3-10 $\mu$. long, with wavelength $c .1 \cdot 25 \mu$. and amplitude $c .0 \cdot 4 \mu$. The lateral flagella stain easily, but except in some strains such as AM and MH, the polar flagellum stains more faintly. These two strains also have polar flagella which are longer than usual (4-6 $\mu$.) though the wavelength is about the same.

The polar flagellum has only been observed arising from the extreme tip of the cell. The lateral ones may show subpolar or lateral attachment.

Flagellar staining is much beset by artifact formation, and therefore some electron micrographs were made for comparison. The same morphological features are seen as in stained preparations (Pl. 1, figs. 3-6). As with stained preparations, previous fixation in $\mathbf{0} \cdot \mathbf{4} \%$ formaldehyde before drying and staining did not alter the shape of the flagella. In lysed organisms a number of basal granules were visible, from which both forms of flagella appeared to originate; these granules are also visible in Pl. 1, fig. 6, which is a cast of the bacterial surface. Houwink \& van Iterson (1950) found in a bacillus isolated by Gray \& Smith (1950) that the polar flagella were thicker than the lateral ones. No difference in thickness was seen in Chromobacterium spp.

It appears unlikely that the flagellar changes are due to multicellularity of the rods during early growth (each cell having one flagellum), since nuclear stains by the acid hydrolysis Giemsa method (Murray, Gillen \& Heagy, 1950) and cell-wall stains by the method of Webb (1954) did not show more numerous nuclei or cross-walls in the peritrichate organisms. Both polar and peritrichate organisms usually showed two or four nuclei, and usually no cross-walls.

\section{Antigenic difference}

It had been noted that some rabbit antisera gave only partial agglutination of some strains over a wide range of serum dilutions, as if the suspension contained two antigenic types. This suggested that the antigens of the polar and lateral flagella were different, so that 'polar' suspensions would possess only the polar $\mathbf{H}$ antigen, while 'peritrichate' suspensions would possess both $\mathbf{H}$ antigens. Antisera were therefore made by injecting polar and peritrichate suspensions of strain DK, and a mirror absorption test was performed. The results are shown in Table 1 ; it will be seen that absorption with polar flagellate organisms leaves an antibody fraction ('anti-lateral' antibody) which agglutinates only the peritrichate organisms, and this suggests that the peritrichate organisms contain an extra antigen. It is also clear that the polar suspension 
used for immunization contained some of this additional antigen, which has produced a low titre of antibody.

It seemed possible that the antigens of the polar and peritrichous flagella might be the same, and that the results in Table 1 might be due solely to the smaller amount of flagellar substance on polar-flagellated organisms (which could be as little as $1 / 20$ of that on peritrichate organisms). This is rendered very unlikely by the following experiment. The antiserum against peritrichate

\section{Table 1. Cross-absorption of antisera by suspensions of polar or peritrichate organisms of Chromobacterium sp. strain $D K$}

Serum was absorbed by mixing with an equal volume of a $20 \%(\mathrm{v} / \mathrm{v})$ suspension of packed organisms, and centrifuging after $1 \mathrm{hr}$. at $35^{\circ}$. The titrations were incubated at $56^{\circ}$ for $4 \mathrm{hr}$.

\begin{tabular}{|c|c|c|c|}
\hline \multirow[b]{2}{*}{ Antiserum to } & \multirow[b]{2}{*}{ Absorbed with } & \multicolumn{2}{|c|}{ Titre against } \\
\hline & & $\begin{array}{c}\text { Polar } \\
\text { organisms }\end{array}$ & $\begin{array}{c}\text { Peritrichate } \\
\text { organisms }\end{array}$ \\
\hline $\begin{array}{l}\text { Polar organisms } \\
\text { Polar organisms } \\
\text { Polar organisms }\end{array}$ & $\begin{array}{l}\text { Unabsorbed } \\
\text { Polar organisms } \\
\text { Peritrichate organisms }\end{array}$ & $\begin{array}{r}640 \\
20 \\
40\end{array}$ & $\begin{array}{r}1,280 \\
640 \\
20\end{array}$ \\
\hline $\begin{array}{l}\text { Peritrichate organisms } \\
\text { Peritrichate organisms } \\
\text { Peritrichate organisms }\end{array}$ & $\begin{array}{l}\text { Unabsorbed } \\
\text { Polar organisms } \\
\text { Peritrichate organisms }\end{array}$ & $\begin{array}{r}320 \\
40 \\
40\end{array}$ & $\begin{array}{r}10,240 \\
5,120^{*} \\
1,280 \dagger\end{array}$ \\
\hline
\end{tabular}

\section{Table 2. Fractional absorption of antiserum to peritrichate organisms of Chromobacterium sp. strain $D K$}

Samples $(2 \mathrm{ml}$.) of a dilution of antiserum were mixed with $50 \%(\mathrm{v} / \mathrm{v})$ packed organism suspensions. Saline was added to make $4 \mathrm{ml}$., and the tubes centrifuged after $1 \mathrm{hr}$. at $35^{\circ}$. The absorbed sera were titrated against peritrichate organisms (the serum was too dilute to agglutinate polar organisms) and incubated for $4 \mathrm{hr}$. at $56^{\circ}$.

$\begin{array}{lcc}\begin{array}{c}\text { Absorbing } \\ \text { suspension }\end{array} & \begin{array}{c}\text { Amount of absorbing } \\ \text { suspension added } \\ (\mathrm{ml})\end{array} & \begin{array}{c}\text { Titre against } \\ \text { peritrichate } \\ \text { organisms }\end{array} \\ \text { Unabsorbed } & 0 & 32 \\ \text { Peritrichate } & 0.002 & 8 \\ \text { Peritrichate } & 0.02 & 2 \\ \text { Peritrichate } & 0.4 & 0 \\ \text { Polar } & 0.4 & 16\end{array}$

organisms was diluted so as to give a final titre of 32 with peritrichate organisms, and was absorbed with various amounts of polar and of peritrichate organisms. It is seen (Table 2) that the polar organisms have less absorbing power than $1 / 200$ of the same amount of peritrichate organisms. These results might also be due to the production of an extra $\mathbf{O}$ antigen under the conditions causing peritrichate flagellation. This is an unlikely explanation, since peritrichate organisms which had been deflagellated in a Waring Blendor were inagglutinable by the absorbed 'anti-lateral' serum. Also the agglutination of peritrichate organisms was typical flocculent ' $H$ ' agglutination, appearing within $2 \mathrm{hr}$. Similar purification of an 'anti-lateral' $\mathbf{H}$ antibody was also obtained 
with strain $\mathrm{BN}$, by absorbing an anti-BN ' $\mathrm{OH}$ ' antiserum with polar-flagellated organisms of that strain.

Positive proof of the existence of a 'polar' antigen was obtained by incubating agglutination tests for $18 \mathrm{hr}$. at $56^{\circ}$. It was noted by Gardner \& Venkatraman (1935) that long incubation at high temperatures was needed to produce $\mathbf{H}$ agglutination of the monotrichate cholera vibrio, evidently because monotrichate organisms form large agglutinates with difficulty. A sample of antiserum against polar-flagellated organisms of strain DK was absorbed with an equal volume of a $50 \%$ suspension of polar organisms which had been deflagellated in a Waring Blendor, and the absorbed serum was titrated against deflagellated polar and peritrichate suspensions (incubated $18 \mathrm{hr} .56^{\circ}$ ). The results (Table 3) show that an antibody fraction remains which agglutinates polar suspensions but not deflagellated suspensions. This fraction was removed when the absorbed serum was absorbed with polar organisms. Similar results were obtained when living suspensions were used for absorption and agglutination. The agglutination was a fine, flaky type not unlike $O$ agglutination, and did not appear after incubation for $4 \mathrm{hr}$. at $56^{\circ}$ followed by standing at $20^{\circ}$ overnight.

Table 3. Absorption of antiserum against polar flagellated organisms of Chromobacterium sp. strain $D K$ to demonstrate polar ' $H$ ' agglutination

\begin{tabular}{lccc}
\cline { 3 - 4 } & $\begin{array}{c}\text { Deflagellated } \\
\text { organisms }\end{array}$ & $\begin{array}{c}\text { Polar } \\
\text { organisms }\end{array}$ & $\begin{array}{c}\text { Peritrichate } \\
\text { organisms }\end{array}$ \\
Unabsorbed serum & 256 & 512 & 512 \\
$\begin{array}{c}\text { Serum absorbed with } \\
\text { deflagellated organisms }\end{array}$ & 8 & $128^{\circ}$ & $\mathbf{2 5 6}$
\end{tabular}

* The titre was decreased to 64 by a second absorption with deflagellated organisms, but was decreased to 8 by an absorption with polar organisms.

The antigen of the polar flagella is thus evidently distinct from that of the lateral flagella, since the lateral $\mathrm{H}$ antibody does not agglutinate polar organisms (a sample absorbed twice with polar organisms had, at $56^{\circ}$ for $18 \mathrm{hr}$., a titre of 2048 with peritrichate organisms, but a titre of only 2 with polar and with deflagellated organisms), nor do polar organisms absorb this antibody. The polar $\mathrm{H}$ antiserum contained lateral $\mathrm{H}$ antibody (see Tables 1 and 3 ); it was not possible to remove this by further absorption, since peritrichate organisms also have polar flagella, and both antibodies were removed by them. No variants lacking the polar flagellum have so far been found and therefore pure polar $\mathbf{H}$ antisera cannot yet be prepared by absorption with peritrichate organisms. As seen in Table 1, polar suspensions contain enough lateral flagella, a good antigen in rabbits, to induce formation of lateral $\mathbf{H}$ antibody.

\section{Effect of cultural conditions upon the type of flagellation}

The strains DK and LG were studied intensively in an attempt to discover the cause of the flagellar changes. This has not been found, but it was observed that lateral flagella were abundant (3-6/organism) in young nutrient agar plate 
cultures, and were most abundant (5-10/organism) in blood agar cultures. Lateral flagella were rare or absent on organisms grown in liquid media. Changes in the following factors did not alter the form of flagellation to any great extent in liquid media: anaerobiosis, aeration, growth temperature, age of culture, growth-pH value, concentration of glucose, amino acids (casein hydrolysate), ammonium, sodium, cyanide, potassium, chloride, phosphate, sulphate, magnesium or calcium ions. Addition of granules of agar to broth or to glucose ammonia medium caused the appearance of a few lateral flagella only. Addition of fresh broth to $18 \mathrm{hr}$. broth cultures did not cause the appearance of lateral flagella. Charcoal had no effect. Growth in liquid exuded from nutrient agar slopes showed mainly polar forms. Lateral flagella were abundant (3-6/organism) in young cultures on silica-gel nutrient broth plates, and cultures upon cellophan floating on nutrient broth also showed many lateral flagella (2-3/organism). Various trace elements were tested without positive results. Attempts to relate the flagellation to the effective viscosity of the medium (which is presumably high within colonies on solid media) were inconclusive.

\section{DISCUSSION}

The appearance of lateral flagella seems to be caused by the environment, and not by the selection of variants, since peritrichate organisms can appear upon a plate in large numbers within $4 \mathrm{hr}$. The variation confirms the observations of Leifson \& Hugh (1953) that some bacteria can possess both polar and lateral flagella-with different antigens in one of their instances. It also raises a question of taxonomic importance, for in Chromobacterium the peculiar flagellation is the rule rather than the exception. It is clear that the form of flagellation, like any other single characteristic, should not be given undue weight in classification. There are instances in which organisms otherwise identical have been placed in separate genera on account of a difference in flagellation (as has happened in Chromobacterium; e.g. Chester (1901) placed Bacillus violaceus Laurentius both in Bacillus and in Pseudomonas because of differing opinions on whether it had peritrichate or polar flagella). Such differences may well be due to unrecognized changes in flagellation caused by the cultural conditions. These observations also indicate the need for standardization of the conditions of growth if the arrangement of flagella is used in classification.

The phenomenon is also of interest in relation to antigenic phase variation in Salmonella. It seems to be assumed that both phases are peritrichate, but I do not know of a study on this point. Three strains of Salmonella (one each of $S$. typhimurium, $S$. cholerae-suis and $S$. paratyphi B) were examined by flagellar staining. In each strain both phases were peritrichate and there was no obvious difference in the flagellar morphology.

The author is indebted to Mr R. Valentine for the electron micrographs. 
Journal of General Microbiology, Vol. 15, No. 1
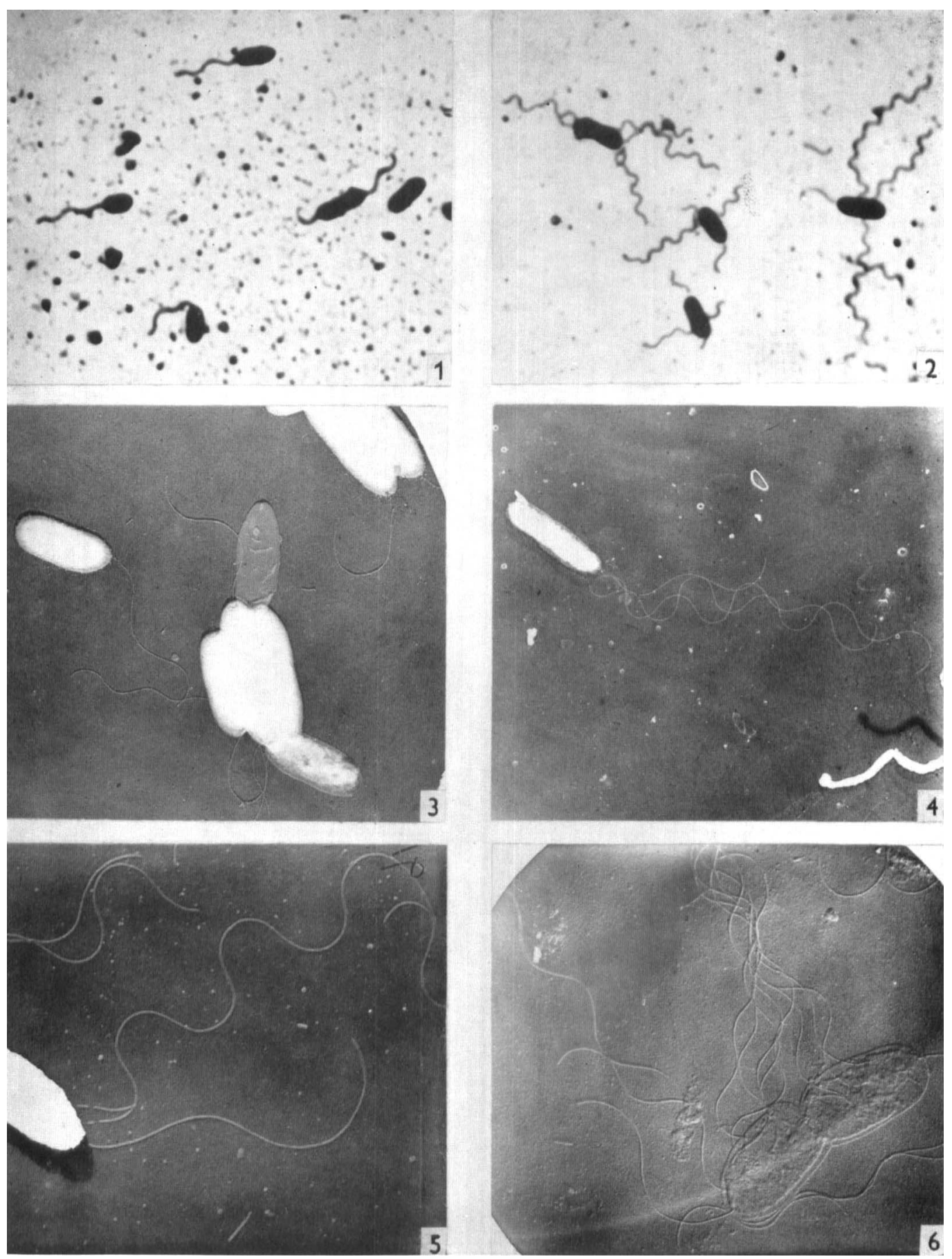

P. H. A. Sneath-Flagela of Chromobacterium spp. Plate 1 
Journal of General Microbiology, Vol. 15, No. 1

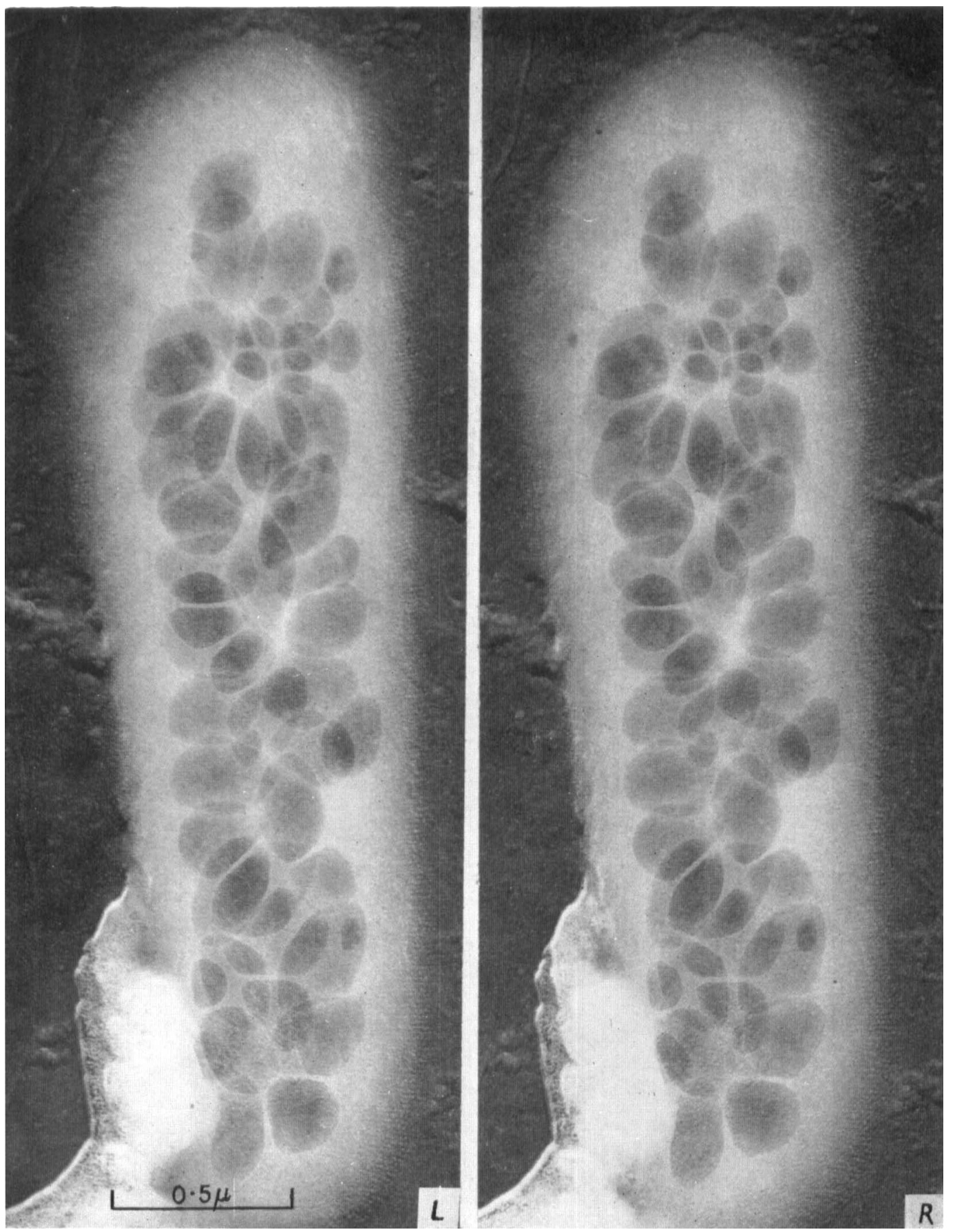

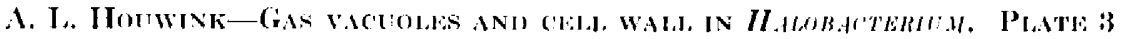


Journal of General Microbiology, Vol. 15, No. 1

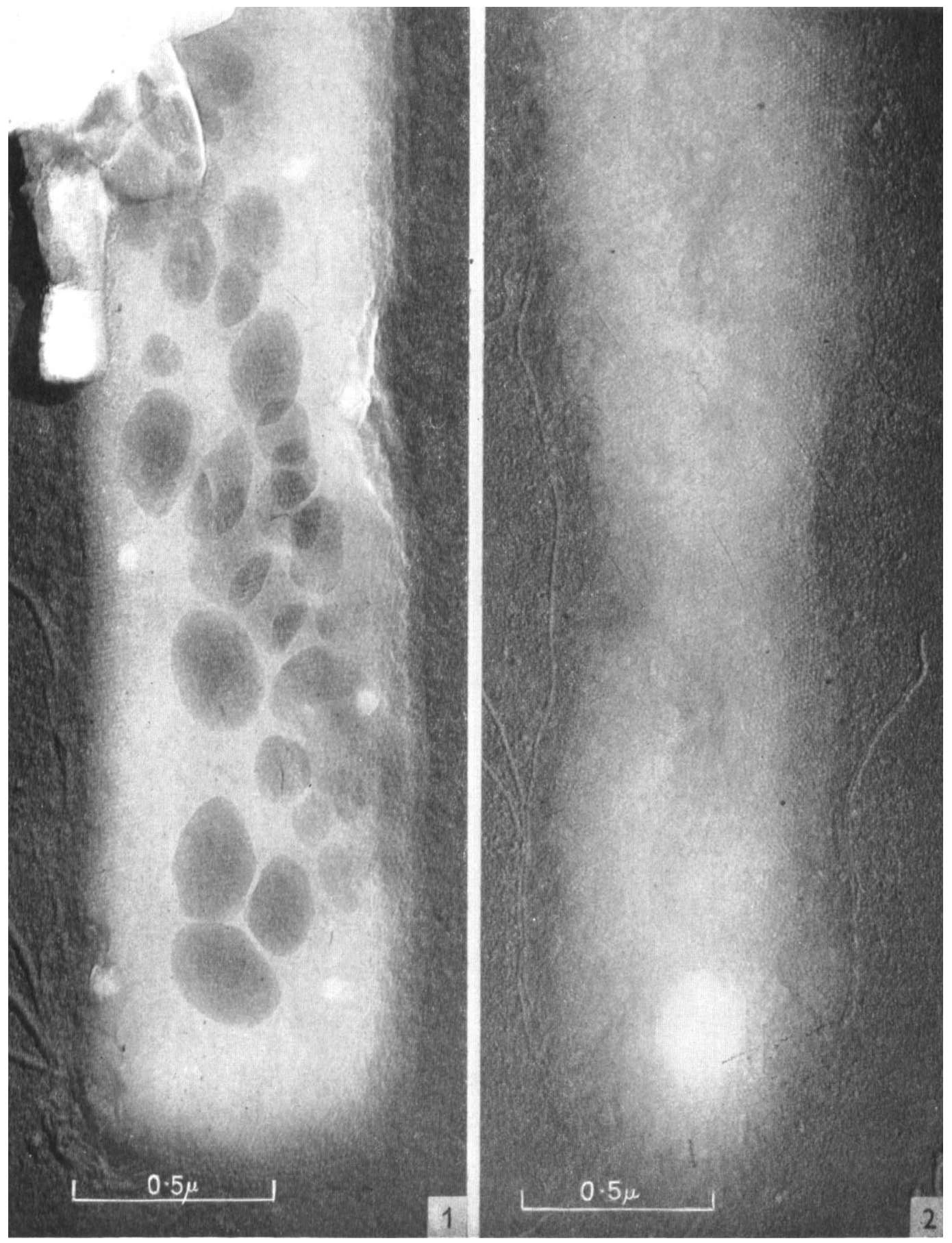

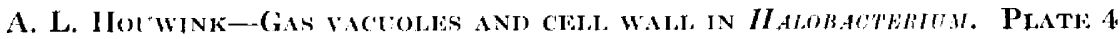




\section{REFERENCES}

Bampton, J. H. (1913). Über Violaceus und Membranaceus amethystinus. Z Zbl. Bakt. (1. Abt. Orig.), 71, 129.

Chester, F. D. (1901). A Manual of Determinative Bacteriology, pp. 262, 317. New York: MacMillan.

Cruess-Callaghan, G. \& Gorman, M. J. (1933). On the characteristics of Bacterium violaceum (Schröter) and some allied species of violet bacteria. Sci. Proc. R. Dublin Soc. 21 (N.S.) (1935), 213.

Gardner, A. D. \& Venkatraman, K. V. (1935). The antigens of the cholera group of vibrios. J. Hyg., Camb. 35, 262.

Gray, E. \& Smith, J. D. (1950). A new aquatic nitrogen-fixing bacterium from three Cambridgeshire chalk streams. J. gen. Microbiol. 4, 281.

Hartley, P. (1922). The value of Douglas's medium for the production of diphtheria toxin. J. Path. Bact. 25, 479.

Houwink, A. L. \& van Iterson, W. (1950). Electron microscopical observations on bacterial cytology. II. A study on flagellation. Biochim. biophys. Acta, 5, 10.

Lehmann, K. B. \& Neumann, R. O. (1899). Atlas und Grundriss der Bakteriologie und Lehrbuch der Speziellen Bakteriologischen Diagnostik. 2e Aufl., 1, pl. 23, figs. XI, XII; 2, p. 180. München: Lehmann.

LEIFSON, E. (1951). Staining, shape and arrangement of bacterial flagella. J. Bact. 62,377 .

LeIrson, E. \& Hugh, R. (1953). Variation in shape and arrangement of bacterial flagella. J. Bact. 65, 263.

MANDELSTAM, J. (1954). Induced biosynthesis of lysine decarboxylase in Bacterium cadaveris. J. gen. Microbiol. 11, 426.

Murray, G. E., Gillen, D. H. \& Heagy, F. C. (1950). Cytological changes in Escherichia coli produced by infection with phage T2. J. Bact. 59, 603.

SNEATH, P. H. A. (1956). Cultural and biochemical characteristics of the genus Chromobacterium. J. gen. Microbiol. 15, 70.

Sneath, P. H. A., Whelan, J. P. F., Singh, R. B. \& Edwards, D. (1953). Fatal infection by Chromobacterium violaceum. Lancet, ii, 276.

WeBB, R. B. (1954). A useful bacterial cell wall stain. J. Bact. 67, 252.

World Health Organization (1954). Expert Committee on Biological Standardization: report of 7th Session, 1953. World Hlth Org. tech. Rep. Ser. no. 86, p. 14.

\section{EXPLANATION OF PLATE}

\section{Plate 1}

Chromobacterium spp.; the flagellation, etc., of various strains.

Fig. 1. Strain $M H$, from $24 \mathrm{hr}$. nutrient agar plate culture. Flagella stain, $\times 2250$. Polar flagellated organisms.

Fig. 2. Strain SH, from $24 \mathrm{hr}$. nutrient agar plate culture. Flagella stain, $\times 2250$. Peritrichate organisms with both polar and lateral flagella.

Fig. 3. Strain DK, from $24 \mathrm{hr}$. nutrient broth culture. Electron micrograph, fixed with $\mathrm{OsO}_{4}$ vapour, platinum shadowed, $\times 7700$. Polar flagellated organisms, and one flagellum of the lateral type.

Fig. 4. Strain DK, from $8 \mathrm{hr}$. nutrient agar plate culture. Electron micrograph, fixed with formalin, carbon shadowed, $\times 8300$. An organism with one polar and two lateral flagella of subpolar origin.

Fig. 5. Strain DK, from $18 \mathrm{hr}$. blood agar plate culture. Electron micrograph, fixed with $\mathrm{OsO}_{4}$ vapour, carbon shadowed, $\times \mathbf{1 6 , 7 6 0}$. Polar and lateral flagella.

Fig. 6. Strain DK from $8 \mathrm{hr}$. blood agar plate culture, fixed with formaldehyde. Electron micrograph of silicon monoxide replica, platinum shadowed, $\times 12,000$. The basal granules of the flagella are faintly shown. 